\title{
Adoption of Integrated Healthcare Information System in Nairobi County: Kenyatta National Hospital versus Mater Hospital
}

\author{
Kirichu Caroline Njeri \\ Faculty of Information \\ Science and Technology \\ Kisii University \\ Nairobi, Kenya
}

\author{
Samuel Matende \\ Associate Faculty \\ Kisii University \\ Nairobi, Kenya
}

\author{
Nicodemus Mokaya \\ Associate Faculty \\ Kisii University \\ Nairobi, Kenya
}

\author{
Jades Kalunda Muema \\ School of Computer \\ Science and Information \\ Technology \\ Dedan Kimathi University \\ Nyeri, Kenya
}

\begin{abstract}
Health care information systems are aimed at facilitating the smooth running and interoperability of the health care delivery processes to ensure efficiency and effectiveness; however, the complexity, heterogeneity and diversity of the health care sector especially in Kenya poses serious challenges especially in relation to integration of the systems. There is a large disconnect between the public and private health care delivery systems characterized by fragmentation of services, locally within hospitals (among primary, secondary and tertiary health care settings) and across different health care centers. This research is aimed at examining the adoption of integrated healthcare information system in Nairobi County; Kenyatta National Hospital represents the public sector and The Mater Hospital the private sector. A sample size of 100 users on information system from the two hospitals picked from the primary secondary and tertiary levels were selected and questionnaires administered to them. Data was analyzed through descriptive statistics with the aid of SPSS. The results of the study indicated that there was a huge disparity between healthcare information system adoption in the public and private sectors with the private sector's adoption being at an advanced stage. The major barriers to adoption including social political barriers, financial constraints and technical/technological barriers also presented.

Keywords: Integrated healthcare, Adoption, Hospital
\end{abstract}

\section{INTRODUCTION}

The introductory chapter covers areas such as the background of the study, statement of the problem, objectives of the study, significance of the study and the conceptual framework.

\subsection{Background of the Study}

Health is a state of complete physical, mental and social well-being and not merely the absence of disease or infirmity (World Health Organisation, 2003). Health care systems are systems which are connected and have independent parts or agents bound by a common purpose and acting on their knowledge (Institute of medicine 2001). Public health care is usually provided by the government through national healthcare institutions. Private health care can be provided through "for profit" hospitals and selfemployed practitioners, and "not for profit" nongovernment providers, including faith-based organizations. Both the private and public sectors have engaged in numerous efforts to promote use of IT within health care institutions and across care delivery settings. (Healthcare Financial Management Association 2004; iHealthBeat, 2003).

In Kenya, the use of information systems in the public health sector is limited. The Government through the Ministry of Health has initiated reforms towards decentralization of health care services and development and integration of Information Technology. However, a large number of these plans have not been successfully implemented. There is a large disconnect between the public and private healthcare sector and the entire health sector as far as information sharing is concerned. The main reason for choosing this topic is due to the fact that successful health care is considered to be the cornerstone of any successful patient-centered health care delivery system and therefore requires special attention to ensure success The Lack of integration and interoperability among the subsystems and cross sector provide a fertile research ground. USAID, (2010).

There is also the need for continuity of care and information exchange within the health sector has introduced an imperative call for successful adoption of health care information system (WHO 2002). There have been numerous attempts to introduce integrated and interoperable health care information system in the public and private healthcare domains with varied results. What has been evident however is the private and public healthcare delivery systems have varied approaches to information systems development and adoption; as such it is important to perform a comparative review of the two with the aim of aiding the health sector to gain from the best of both worlds. Health care information systems are a prerequisite for coordinated, integrated, and evidenceinformed health care (WHO 2002). 


\subsection{Statement of the Problem}

The health care systems in Kenya are typically made up of a number of relatively independent health programs and services which all maintain their own vertical and uncoordinated reporting systems. A patient's medical records are recorded on paper, electronically or a combination of both, and are typically held in different locations. This makes it difficult to get a complete picture of the patient's healthcare journey. Additionally, fragmentation of services, locally within hospitals and between primary, secondary and tertiary health care settings, alongside the use of different information systems in different care settings can make it difficult to safely communicate information. This may lead to miscommunication or missing patient information, ultimately compromising patient safety. The problem of HIS fragmentation and integration of health care information system is consequently a priority that needs to be addressed to realise successful patient centred healthcare delivery in the country. (African Development Bank et al, 2012), Health Information and Quality Authority, Brailer, 2013).

According to Mwangi, (2013). Studies have not only indicated insufficient adoption of HIS system in the country but also a major disconnect between public and private adoption.

Therefore this research seeks to address this problem by comparing healthcare Information System as implemented in both private and public Hospitals.

\subsection{Research Objectives}

The main objective of this research is to study the adoption of integrated healthcare information system in Nairobi County; in this regard KNH will represent public hospitals and The Mater Hospital, private hospitals. The specific objectives in this regard are:

i. To evaluate and compare the existing health care information systems in Nairobi County.

ii. To determine key success factors in the successful adoption of healthcare information system in Nairobi County.

iii. To determine the barriers to successful adoption of healthcare information system in Nairobi County.

\subsection{Significance of the Study}

The findings and recommendations of this study will provide an insight and add to academic knowledge both in the field of Information Systems (and their adoption) and health care delivery. The comparative study will reduce the disparities that exist between the private and public health hospitals together with the insufficient information sharing among the stake holders.

This study will also go a long way in helping the healthcare providers and information systems developers in the development and adoption of health care information systems that are patient-centered, interoperable and integrated to ensure not only effective and efficient operations but also facilitate the sharing of relevant health care information across the health care delivery spectrum.
The knowledge gained from the study will provide great insights and guidelines to the leaders, managers and authorities including the government in decision making, policy formulation, strategic planning and regulation of the health care sector in regards to information management to improve service delivery and improvement of health care. The primary stakeholders of the health care system would also be beneficiaries of this study by adopting and implementing their information systems in a way that they integrate and interoperate with the healthcare system and as such be able to share information.

\subsection{Conceptual Framework}

The conceptual framework uses the attributes of the updated DeLone and McLean (D\&M) information system success model which are also the key success factors for successful implementation (Zaied, 2012); the researcher has also modified the model and included other parameters for evaluation that are important for this study including management support, training, perceived usefulness. It also uses aspects of TAM model (Davis, 1989) to determine the adoption factor of HIS systems. These additional parameters include: Management support, level of training, perceived usefulness, Perceived ease of use, behavioral intention.

Numerous studies have been done on healthcare information system in Kenya both in the public and private sectors. However no study has been done on the comparison of the adoption of integrated health care information system between public and private hospitals in Kenya, more so with focus on integration and interoperability. This research aims to fill this gap in a unique way by modifying the existing model and present a unique perspective of the Kenyan health care information system. 


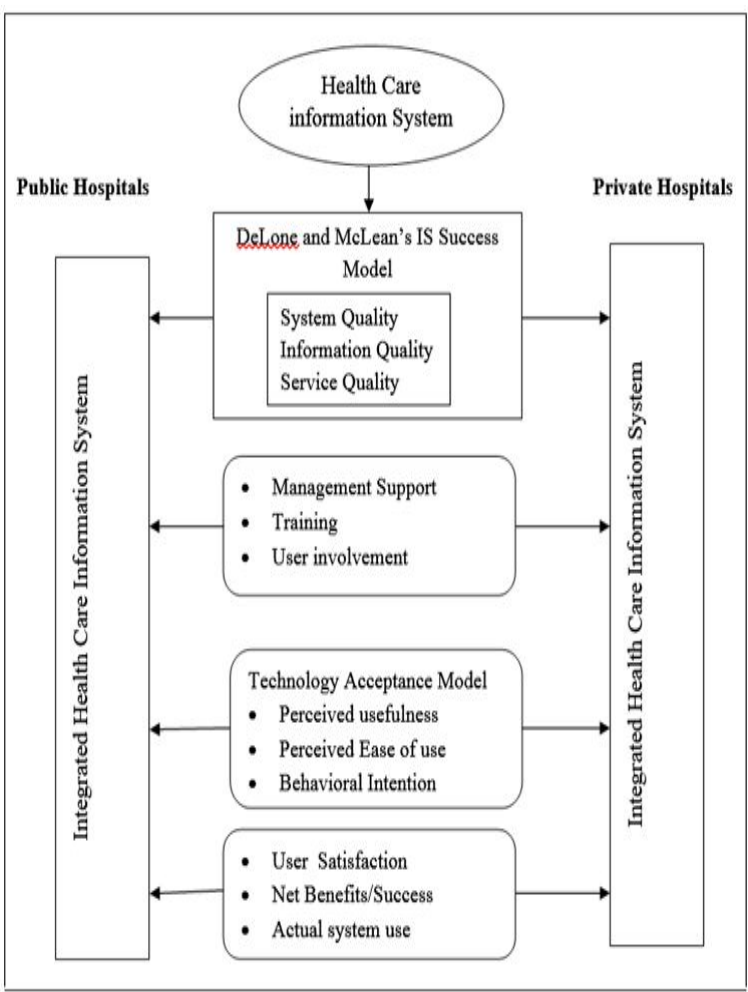

Figure 1: Conceptual Framework

\section{LITERATURE REVIEW}

\subsection{Overview of Healthcare Information Systems}

Health care systems are a set of connected or interdependent parts or agents including care givers and patients bound by a common purpose and acting on their knowledge (Institute of Medicine 2001). Health care information systems that are successfully developed and implemented can improve health care efficiency and effectiveness. Despite its importance, the health care domain has been underrepresented in the debate on the development of information systems from both an empirical as well as theoretical viewpoint. (Fichman et al., 2011; (Callen et al., 2007).

The health care information system management structure consists of the following components: health care information system resources including persons, supplies, and a set of organizational rules (definition of staff responsibilities, supply management procedures, and computer maintenance procedures), to ensure efficient use of health care information system resources. At each level of the hospital organizational structure, health care information system has specific functions that require specific decisions to be made, intended ultimately to improve the health status of the patients. (Nyamtema, 2010; Locatelli, 2010).

\subsection{Healthcare Information Systems Function in Health Care Delivery}

Healthcare information systems facilitate the efficient, effective and timely collection and sharing of relevant and correct data among these stakeholders to ensure patient centered service delivery. In general it is a combination of Health Information and Management Information. Health care information systems are a prerequisite for coordinated, integrated, and evidence-informed health care (HIQA, 2010).

To provide optimal care, healthcare institutions need timely patient information from various sources at the point-ofcare, and need a comprehensive, complete and fully functional system to fulfil all these needs. One way to achieve this is through the use of IS in health care. Appropriate information and Health care Information Systems are seen as crucial to strengthening the health system in developing countries and in pursuing the particular MDGs. Successful systems are most likely to be the ones that offer opportunities for ongoing professional involvement, relative stability and security, and the capacity to support improvements in practice with useful and timely information. (AbouZahr and Boerma, 2005; WHO, 2004, HIQA, 2010).

\subsection{Health Care Organization and Management of Public and Private Hospitals in Kenya}

The health sector in Kenya comprises the public and private health care providers. A typical patient journey should start with contact with primary care for an initial diagnostic consultation, and might then involve the patient being referred to secondary care for more specialized treatment, or a tertiary service for even more specialized follow-up. (Walshe and Smith, 2010). However, these sectors overlap and it is frequently true that an individual patient may receive services within more than one sector at the same time (Walshe and Smith, 2010; Lapão and Dussault, 2012).

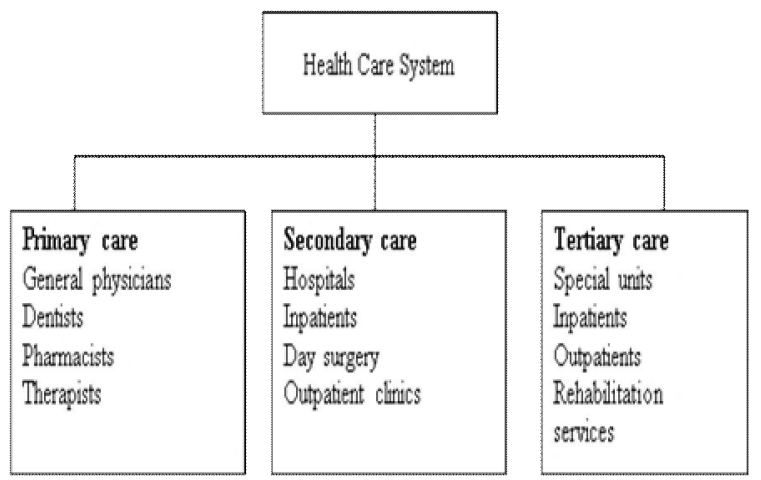

Figure 2: Generic structure of a healthcare system (Walshe and Smith, 2010) 


\subsection{Health Care Information Systems Success Model}

Different approaches have been developed concerning information systems evaluation and each of them have both positive characteristics and flaws as well. The evaluation of a system in terms of its success is an inherently complex phenomenon. It is of vital importance that during the evaluation process both the technology that is used and the role of the users that participate and their relation to the technology must be taken into account. (Prodromos et al, 2012). For this study the researcher will use two theoretical models; the Technology Acceptance Model (TAM) and the updated DeLone and McLean's Model.

The TAM model, developed by Davis (1989) is used to measure the acceptance, adoption and use of information technology. It is very popular and two constructs are used in TAM, perceived ease of use and perceived usefulness. TAM indicates the relationship between external variables, perceived useful-ness, perceived ease of use, attitude toward use and actual usage. TAM provides information on how the design choices influence user acceptance of technology. According to Davis, if the system appears useful to the users then they are more willing to use it. (Prodromos et al, 2012). Perceived usefulness is the degree to which an individual believes that using a particular information system or information technology would enhance his or her job. Perceived ease of use is the degree to which a person believes that using a particular information technology would be free of effort. TAM model has gained wide popularity among the researchers and is one of the most influential model. This is different from other models as it does not measure success but it is used to study and predict the user's intention to use IT. (Davis, 1989; Prodromos et al, 2012).

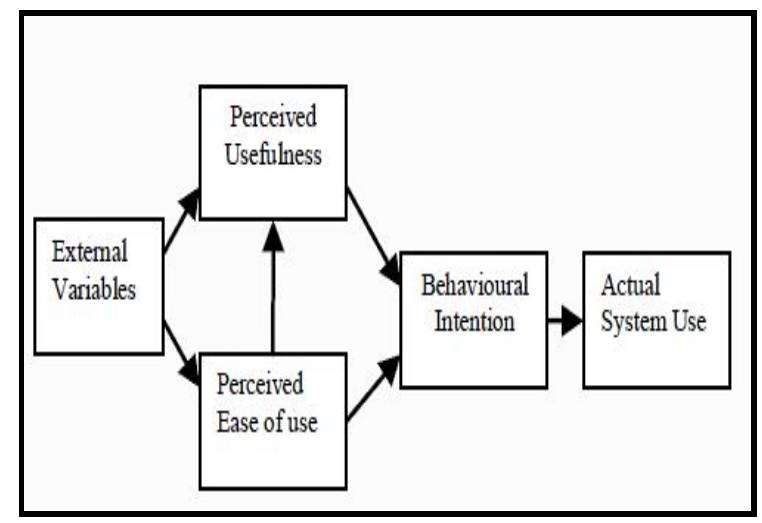

Figure 3: Technology Acceptance Model (Davis, 1989)

Six dimensions of IS success have been identified by DeLoan and McLean: system quality, information quality, information use, individual impact, and organizational impact. All these six dimensions characterize an IS both from the organizational viewpoint and the socio-technical viewpoint. Later added one more dimension, service quality. (Prodromos et al, 2012).

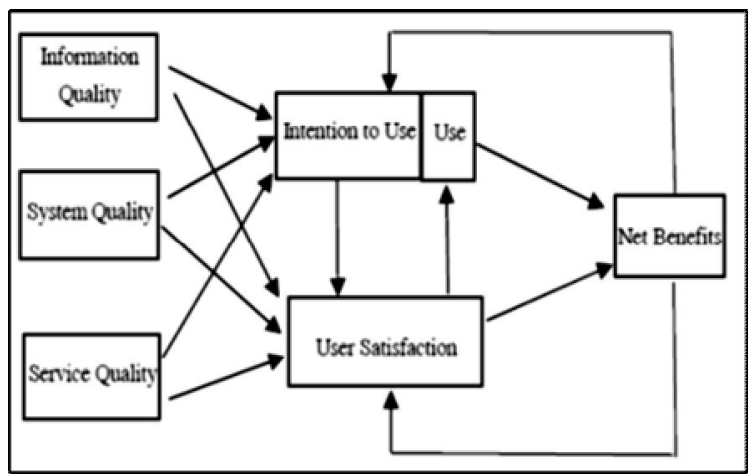

Figure 4: The updated DeLone and McLean's Model. (Zaied, 2012)

The following parameters adopted from updated DeLone and McLean's Model were used to interrogate the private and public health care information systems and bring forth the key success factors; system quality, information quality, service quality, system use, user satisfaction, and net benefits. (Nasser, 2012; Zaied, 2012).

\section{RESEARCH METHODOLOGY}

The target population of the research was end users in the health care facilities who interact directly with the information system at various levels in the hospitals organization structure primary, secondary and tertiary care. These include the hospitals point of entry, pharmacy, laboratories, and all other departments. Managers and Information system professionals were excluded. To facilitate data collection, the study's sampling frame constituting of respondents from the $\mathrm{KNH}$, The Mater Hospital that are end users of their respective healthcare information system. The researcher used a sample size of 100 respondents from the population of 133 end users to who questionnaires were administered to collect data which was analyzed using SPSS. Descriptive statistics is used to describe the basic features of the data in this study.

\section{DATA PRESENTATION, ANALYSIS, RESULTS AND DISCUSSIONS}

\subsection{General Information about Respondents Participation}

The study was conducted at The Matter Hospital and Kenyatta National Hospital with $50 \%$ of the respondents picked from each hospital as indicated in table 1.

Table 1: Respondents participation

\begin{tabular}{cccc}
\hline \hline Sector & $\begin{array}{c}\text { Target } \\
\text { Population }\end{array}$ & Responses & Rate \\
\hline Public & 50 & 50 & $100 \%$ \\
Private & 50 & 50 & $100 \%$ \\
Total & 100 & 10 & $100 \%$ \\
\hline \hline
\end{tabular}

There was $100 \%$ response rate in this study, this could be attributed to the consistent follow up by the research team who were on standby to provide explanation and answer any questions from the respondents. The fact that permission was sought from immediate superiors some of whom participated in the research and requested their juniors to participate is also a factor in this 
response rate. This response rate therefore means that the study is valid.

\subsection{System quality}

The descriptive statistics table 2 shows the total number of variables that were involved in the analysis. Maintainability, usability and interoperability were the system quality factors considered by most respondents.

Table 2: System quality

\begin{tabular}{cccc}
\hline \hline System Quality & Mean & $\begin{array}{c}\text { Std. } \\
\text { Deviation }\end{array}$ & $\begin{array}{c}\text { Analysis } \\
\text { N }\end{array}$ \\
\hline Reliability & 2.07 & .871 & 100 \\
Usability & 2.80 & 1.285 & 100 \\
Adaptability & 2.36 & 1.227 & 100 \\
Trust & 2.13 & 1.010 & 100 \\
Maintainability & 4.07 & 1.006 & 100 \\
Integration & 2.46 & 1.206 & 100 \\
Interoperability & 2.52 & 1.293 & 100 \\
\hline \hline
\end{tabular}

\subsection{Information quality}

Table 3 indicates the factors variables that were involved in the analysis on regards to information quality. Majority of the respondents felt that information availability, security and accuracy with a mean of $3.75,3.20$ and 3.07 respectively were the key factors in the determination of its quality.

Table 3: Information quality

\begin{tabular}{|c|c|c|c|}
\hline & Mean & $\begin{array}{c}\text { Std. } \\
\text { Deviation }\end{array}$ & Analysis N \\
\hline Completeness & 2.66 & 1.210 & 100 \\
\hline Understandability & 2.82 & 1.208 & 100 \\
\hline Security & 3.20 & 1.212 & 100 \\
\hline Availability & 3.75 & 1.164 & 100 \\
\hline Accuracy & 3.07 & 1.305 & 100 \\
\hline
\end{tabular}

\subsection{Service Quality}

According to the survey and as indicated in table 4, information system efficiency and functionality with a mean of 6.32 and 5.95 were regarded as the most significant variables when determining its service quality.

Table 4: Service quality

\begin{tabular}{llll}
\hline \hline & Mean & Std. Deviation & Analysis N \\
\hline Reliability & 2.75 & 1.268 & 100 \\
Integrity & 5.18 & 3.406 & 100 \\
Functionality & 5.95 & 3.083 & 100 \\
& & & 100 \\
Efficiency & 6.32 & 3.369 & \\
\hline \hline
\end{tabular}

\subsection{Management Support}

In Mater hospital the respondents unanimously agreed that the management supports the adoption and use of HIS in all its daily operations not only by encouraging of the use of the system but also by addressing the problems associated with the system. This is shown in table 5 below.

Table 5: Management Support - Mater

\begin{tabular}{ccccc}
\hline \hline & \multicolumn{2}{c}{ Discuss HIS Problems } & \multicolumn{2}{c}{ Encourage HIS use } \\
& Frequency & Percentage & Frequency & Percentage \\
\hline Neutral & 3 & 6 & 0 & 0 \\
Agree & 6 & 12 & 2 & 4 \\
$\begin{array}{c}\text { Strongly } \\
\text { disagree }\end{array}$ & 41 & 82 & 48 & 96 \\
Total & 50 & 100 & 50 & 100 \\
\hline \hline
\end{tabular}

In $\mathrm{KNH}$ on the other hand over $60 \%$ of the respondents felt that the management was supporting the adoption and use of HIS as indicated in table 6. However the breadth of support in Mater is greater than that $\mathrm{KNH}$.

Table 6: Management Support - KNH

\begin{tabular}{ccccc}
\hline \hline & \multicolumn{2}{c}{ Discuss HIS Problems } & \multicolumn{2}{c}{ Encourage HIS use } \\
& Frequency & Percentage & Frequency & Percentage \\
\hline Disagree & 0 & 0 & 4 & 8 \\
Neutral & 12 & 24 & 8 & 16 \\
Agree & 30 & 60 & 36 & 72 \\
Strongly & 8 & 16 & 2 & 4 \\
disagree & 50 & 100 & 50 & 100 \\
Total & 50 & &
\end{tabular}

\subsection{User involvement}

Table 7: User involvement - Mater Hospital

\begin{tabular}{ccccc}
\hline \hline & $\begin{array}{c}\text { Involvement in input } \\
\text { design }\end{array}$ & \multicolumn{2}{c}{$\begin{array}{c}\text { Involvement in output } \\
\text { design }\end{array}$} \\
& Frequency & Percentage & Frequency & Percentage \\
\hline $\begin{array}{c}\text { Strongly } \\
\text { Disagree }\end{array}$ & 42 & 84 & 42 & 84 \\
Disagree & 3 & 6 & 3 & 6 \\
Total & 50 & 100 & 50 & 100 \\
\hline \hline
\end{tabular}

The survey shows that both The Mater hospital and KNH did not involve their users during HIS development according to $84 \%$ and $96 \%$ of the respondents even in issues that directly affect them including involvement in output and input design as indicated in tables 4.19 and 4.20

Table 8: User involvement - KNH 
Frequency Percentage Frequency Percentage

\begin{tabular}{ccccc}
\hline $\begin{array}{c}\text { Strongly } \\
\text { Disagree }\end{array}$ & 48 & 96 & 48 & 96 \\
Disagree & 2 & 4 & 2 & 4 \\
Total & 50 & 100 & 50 & 100 \\
\hline \hline
\end{tabular}

\subsection{Perceived ease of use}

The descriptive statistics table 9 shows the total number of variables that were involved in the analysis. According to the survey, the respondents felt that the IS should be easy to learn, compatible and simple.

Table 9: Perceived ease of use

\begin{tabular}{cccc}
\hline \hline & Mean & $\begin{array}{c}\text { Std. } \\
\text { Deviation }\end{array}$ & $\begin{array}{c}\text { Analysis } \\
\mathbf{N}\end{array}$ \\
\hline Easy to learn & 7.46 & 3.443 & 100 \\
Easy to manage & 1.93 & .912 & 100 \\
Self-efficiency & 1.91 & 1.032 & 100 \\
Simplicity & 2.93 & 1.248 & 100 \\
Compatibility & 2.71 & .967 & 100 \\
\hline \hline
\end{tabular}

Table 10: Behavioral intention

\begin{tabular}{cccc}
\hline \hline & Mean & $\begin{array}{c}\text { Std. } \\
\text { Deviation }\end{array}$ & $\begin{array}{c}\text { Analysis } \\
\text { N }\end{array}$ \\
\hline Personalization & 2.27 & 1.328 & 100 \\
Response time & 1.84 & .930 & 100 \\
Interactivity & 2.45 & 1.334 & 100 \\
Uncertainty avoidance & 3.02 & 1.198 & 100 \\
$\begin{array}{c}\text { Number of transactions } \\
\text { executed. }\end{array}$ & 3.32 & 1.064 & 100 \\
\hline \hline
\end{tabular}

According to the survey, number of transactions executed (mean 3.32) and uncertainty avoidance (3.02) were regarded as the most influential factors on their behavioral intention to use HIS as shown in table 10.

\subsection{User satisfaction}

The survey response indicates that as far as user satisfaction is concerned, the majority of the respondents were of the opinion that self-efficacy was the most important factor with a mean of 3.20 followed by personalization with a mean of 2.77 as indicated in table 10 .

Table 10: User satisfaction

\begin{tabular}{cccc}
\hline \hline & Mean & $\begin{array}{c}\text { Std. } \\
\text { Deviation }\end{array}$ & $\begin{array}{c}\text { Analysis } \\
\text { N }\end{array}$ \\
\hline Self-efficacy & 3.20 & 1.086 & 100 \\
Personalization & 2.77 & .972 & 100 \\
Perceived risk & 1.86 & .883 & 100 \\
Enjoyment & 2.23 & 1.079 & 100 \\
\hline \hline
\end{tabular}

\subsection{Barriers to Adoption of Health} Care Information System:

The survey showed that majority of the respondents felt that social political barriers were the most significant with a mean of 8.21, followed by time constraints and technical technological factors as indicated in table 11.

Table 10: Barriers to Adoption of Health Care Information System

\begin{tabular}{cccc}
\hline \hline & Mean & $\begin{array}{c}\text { Std. } \\
\text { Deviation }\end{array}$ & $\begin{array}{c}\text { Analysis } \\
\text { N }\end{array}$ \\
\hline Financial constraints & 4.84 & 3.627 & 100 \\
Technical/Technology & 6.70 & 3.613 & 100 \\
$\quad$ Time constraints & 7.84 & 3.468 & 100 \\
$\begin{array}{c}\text { Social political } \\
\text { barriers }\end{array}$ & 8.21 & 3.789 & 100 \\
$\begin{array}{c}\text { Organizational } \\
\text { (structural) }\end{array}$ & 2.02 & .924 & 100 \\
$\quad$ Change Process & 2.46 & 1.361 & 100 \\
\hline \hline
\end{tabular}

\section{SUMMARY OF RESEARCH FINDINGS}

Both Mater hospital and KNH use a combination of both IS and paper based systems, however the level of HIS use in Mater hospital is far more extensive than that of $\mathrm{KNH}$. Mater hospitals' HIS is viewed as to have had significant influence in ensuring effectiveness and efficiency of healthcare delivery than that of KNH. This could be attributed to its extensive use and interoperability. This is however not the case for KNH whose activities are mainly paper based and as such computerized HIS have not had as much impact on healthcare delivery. Mater hospital uses information Technology to manage virtually all their health information including collection, processing, storage, transmission, and retrieval. KNH on the other hand health information management is a combination of both paper based and computer based health information management with the later taking precedence and as such their computerized information management not as effective.

In regards to HIS information quality the users regarded reliability, maintainability and adaptability respectively as the most desirable features to ensure successful adoption. In relation to information the study determined that to the users of ranked highly information availability and security. In regard to service quality, the HIS users considered system functionality and efficiency as the most desired quality. Management's encouragement, discussing problems associated with the system were rated highly by users as being key in ensuring successful HIS adoption. The users felt that it was important that they be involved especially in the input and output design. To determine the perceived usefulness of the HIS users mostly looked at whether the system would lead to improved productivity and improved performance as key measures to determine the systems perceived usefulness of the IS. Enjoyment and 
self-efficacy of the system were regarded as the key factors when it came to users' satisfaction.

The study indicated that social political barriers, financial constraints and technical/technological barriers were the major barriers to the successful adoption of HIS.

\section{CONCLUSION}

Both the private and public sector have adopted HIS into their hospitals with mixed results. Mater hospitals has a higher level of integration of HIS and information technology into their activities in general compared to $\mathrm{KNH}$. The HIS users in Mater hospital with the encouragement and policies of the management (including training) use their HIS in most if not all of their information management; they also do not feel that there is need for significant reforms in their HIS implying that overall the system is sufficient to ensure efficient and effective health care delivery.

The users in KNH feel that their system is in dire need of significant reforms and support from the management (including training and provision of training materials on the system) to ensure successful use and improve service delivery. In regards to successful adoption of HIS system the desired characteristics were similar across the board. Social political barriers, time constraints and technical/technological barriers were deemed as the most significant barriers to successful HIS in the health care sector in Nairobi County.

\section{RECOMMENDATIONS}

In the view of the findings of the research, the researcher recommends that the key stakeholders in the healthcare sector device an approach that would ensure a successful adoption of HIS that is integrated and interoperable across both the private and public sector. The public sector should learn from the private sector how they have managed to successfully adopt and use HIS to improve health care service delivery and make amends on their approach. Users of HIS are seldom involved in the system design and as such their input should be sought and considered especially considering they will be the ones to use the systems and as such their needs and requirements should be considered. The healthcare sector managers should encourage and insist on the use of HIS and provide the necessary support in terms of resource allocation and involvement for successful adoption.

The barriers to successful adoption should be addressed and be minimized if not eliminated to ensure not only successful adoption but also improvement in health care service delivery.

\section{Suggested area for further study}

The three most significant barriers to successful HIS adoption in Nairobi County should be addressed if the sector is to ensure efficient and effective service delivery. The researcher therefore suggests that studies be carried out to determine systematic approaches that would be used to minimize this impediments from their root causes and ensure successful adoption of HIS in an effort to provide efficient and effective patient centered health care delivery. Further studies should focus on implementation of HIS that are not sector centered but ones that cut across the board

\section{REFERENCES}

Anderson, G. (2009). Improving Patient Safety with Information Technology, In: Handbook of Research on Advances in Health Informatics and Electronic Healthcare Application, Khoumbati, et al (Eds.), pp. 1-16, Medical Information Science Reference, ISBN 978-1-60566-030-1, Hershey (PA).

Brailer J. (2013). Interoperability: The Key to the Future Health Care System. Health Affairs. http://www.ncbi.nlm.nih.gov/pubmed/15659454. Accessed on: 2927 February 2014.

Casey G. et al. (2012). Introduction to Information System: Support and Transforming Business (Fourth Edition). New Jersey: John Wiley and Sons, Inc.

Christensen M. et al; (2009). The Innovator's Prescription: A Disruptive Solution for Health Care, McGraw-Hill, ISBN 978-0-07-159209-3, New York

Davis, F. (1989). Perceived Usefulness, Perceived Ease of Use, and User Acceptance of Information Technolo-gy. MIS Quarterly 13 (3), 319-340.

Finchman, G. et al (2011). Editorial Overview - The role of IS in Healthcare. Information Systems Research, Vol. 22, No. 3, pp. 419-428

Floden J. (2013). Essentials of Information Systems. Gazelle Book Services.

Gay R. and Peter A. (2012). Selecting Samples. Prentice Hall. Upper Saddle River, New Jersey, Columbus Ohio.

Government of Kenya (2007). Kenya Vision 2030. A Globally Competitive and Prosperous Kenya.

Health Information and Quality Authority. (2013). Developing National eHealth Interoperability Standards for Ireland: A Consultation Document. Health Information and Quality Authority Dublin Regional Office George's Court George's Lane Smithfield Dublin 7.

Healthcare Financial Management Association. 2004. Financing the future report 2: How are hospitals financing the future? The future of capital spending. Westchester, IL: HFMA.

IHCO (2011). ICT in Health Care: Innovation in Search of an Author, School of Management of Politecnico di Milano.

Kaplan, R. and Porter, M. (2011) How to solve the cost crisis in health care, Harvard Business Review. 
International Journal of Computer Applications Technology and Research Volume 3-Issue 11, 685 - 692, 2014, ISSN: 2319-8656

Mwangi C. (2013). Computerization of the Kenyan Health Care Records. Helsinki Metropolia University of Applied Sciences. Helsinki.

Nasser H. (2012). An Integrated Success Model for Evaluating Information System in Public Sectors. Journal of Emerging Trends in Computing and Information Sciences. VOL. 3, NO. 6, ISSN 2079-8407

Nyamtema S. (2010). Bridging the gaps in the Health Management Information System in the context of a changing health sector. BMC Medical Informatics and Decision Making, vol. 10, pp. 1-36.

Prodromos D. et al (2012). Hospital Information System Evaluation. 10th International Conference on Information Communication Technologies in Health, Samos Island Greece

Rada, R. (2008). Information Systems and Healthcare Enterprises, IGI Publishing, Hershey (PA)

Rainer R.et al (2013). Introduction to Information Systems, Third Canadian Edition. John Wiley $\backslash \&$ Sons Canada, Limited

Reynolds G. and, Stair R. (2013). Information System Essentials. Cengage South-Western

Rolli, J. (2012). Fundamentals of Information Systems. SeyfKashani, NajibeAfnan, Semat Publications, Tehran.

Sandiford, P. et al (1992). What can Information Systems do for Primary Health Care? An International Perspective, Social Science and Medicine (34:10), pp. 1077-1087.

United States Agency for International Development. (USAID), (2010). Kenya Health System Assessment 2010. Bethesda, MD: Health Systems 20/20 project, Abt Associates Inc.

Zaied H. (2012). An Integrated Success Model for Evaluating Information System in Public Sectors. Journal of Emerging Trends in Computing and Information Sciences. VOL. 3, NO. 6. CIS Journal. ISSN 2079-8407. 